\title{
REVIEW
}

\section{Fixed-Dose Combination of Canagliflozin and Metformin for the Treatment of Type 2 Diabetes: An Overview}

Jaime A. Davidson · Lance Sloan

Received: August 16, 2016 / Published online: November 16, 2016

(C) The Author(s) 2016. This article is published with open access at Springerlink.com

\section{ABSTRACT}

Metformin is recommended as a first-line therapy for patients with type 2 diabetes mellitus (T2DM). However, many patients do not achieve glycemic goals with metformin monotherapy and require subsequent combination therapy with other antihyperglycemic agents (AHAs). For newly diagnosed patients with high blood glucose, initial combination therapy may be required to achieve glycemic control. The American Association for Clinical Endocrinologists algorithm for the treatment of T2DM recommends metformin plus a sodium glucose co-transporter 2 (SGLT2) inhibitor as the first oral combination in patients who present with HbA1c $\geq 7.5 \%$. Canagliflozin, an SGLT2

Enhanced content To view enhanced content for this article go to http://www.medengine.com/Redeem/ 3D07F0603A840C8F.

\section{J. A. Davidson ( $\square)$}

Department of Medicine, Touchstone Diabetes Center, University of Texas Southwestern Medical Center, Dallas, TX, USA

e-mail: jaime.davidson@utsouthwestern.edu

L. Sloan

Texas Institute for Kidney and Endocrine Disorders, Lufkin, TX, USA inhibitor, lowers the renal threshold for glucose and increases urinary glucose excretion leading to a mild osmotic diuresis and a net caloric loss. The effect of canagliflozin is insulin-independent and complementary to other AHAs, including metformin. A fixed-dose combination (FDC) of canagliflozin and metformin is also available with variable dosing, which may be attractive to some patients owing to the potential for reduced pill burden and costs. This article reviews the efficacy and safety of canagliflozin in combination with metformin based on data from the canagliflozin phase 3 clinical program. As initial combination therapy in drug-naïve patients or as dual therapy with metformin or triple therapy in combination with metformin and other AHAs, canagliflozin 100 and $300 \mathrm{mg}$ improved glycemic control and provided reductions in body weight and systolic blood pressure that were sustained for up to 104 weeks. Canagliflozin was generally well tolerated across studies in combination with metformin. An increased incidence of adverse events (AEs) related to the mechanism of SGLT2 inhibition (i.e., genital mycotic infections, urinary tract infections, osmotic 
diuresis-related AEs) was observed with canagliflozin. Canagliflozin was associated with a low incidence of hypoglycemia when not used in conjunction with AHAs associated with hypoglycemia (i.e., insulin or sulfonylurea). Together, these results support the use of a canagliflozin and metformin FDC as a treatment approach for a broad range of patients with T2DM.

Funding: Janssen Scientific Affairs, LLC.

Keywords: Canagliflozin;

Efficacy;

Endocrinology; Fixed-dose combination; Metformin; Safety; Sodium glucose co-transporter 2 inhibitors; Type 2 diabetes mellitus

\section{INTRODUCTION}

Clinical practice guidelines recommend metformin as a first-line pharmacologic therapy for the management of type 2 diabetes mellitus (T2DM) [1-3]. Metformin works by decreasing hepatic glucose production and intestinal glucose absorption and by improving insulin sensitivity, thereby enhancing peripheral glucose uptake [4, 5]. Enhanced excretion of glucagon-like peptide-1 with metformin may contribute to the intestinal glucose-lowering activity [6, 7]. Metformin may not be tolerated in all patients because of gastrointestinal side effects $[8,9]$.

Due to the progressive nature of T2DM, most patients eventually require combination therapy with other antihyperglycemic agents (AHAs) [2, 10, 11]. In addition, many patients can receive initial combination therapy at the time of diabetes diagnosis in order to reach glycemic goals efficiently. The guidelines related to the use of combination therapy vary among national and regional organizations. For example, the American Diabetes Association supports initiation of dual therapy in newly diagnosed patients with T2DM and HbA1c $\geq 9.0 \%$ [2]. The American Association of Clinical Endocrinologists (AACE) takes a more aggressive approach, recommending initial combination therapy for patients with HbA1c $\geq 7.5 \%$ [1]. The Texas Diabetes Council gives an option for initiation of monotherapy in patients who present with $\mathrm{HbA1c}<1 \%$ above their individualized goal; in patients with HbA1c $>1.0 \%$ above their goal, initial combination therapy is recommended [12].

Sodium glucose co-transporter 2 (SGLT2) inhibitors are recommended by AACE as the first oral add-on for patients inadequately controlled on metformin [1]. Canagliflozin, an SGLT2 inhibitor, lowers plasma glucose levels in patients with T2DM by increasing urinary glucose excretion, resulting in a mild osmotic diuresis and a net caloric loss [13]. This insulin-independent mechanism of action is complementary to other types of AHAs, including metformin [2]. Across phase 3 trials, as monotherapy or in combination with metformin or other AHAs, canagliflozin 100 and $300 \mathrm{mg}$ have been shown to provide not only glycemic improvement but also weight loss and blood pressure (BP) lowering in a broad range of patients with T2DM [14]. An oral fixed-dose combination (FDC) tablet of canagliflozin and metformin immediate release (IR) was approved in 2014 for the treatment of adults with T2DM [15], and findings from a study of initial combination therapy with canagliflozin plus metformin extended release (XR) have recently been published [16]. This review summarizes the clinical data in support of the canagliflozin and metformin FDC. This article is based on previously conducted studies and does not involve any new studies of human or animal subjects performed by any of the authors. 


\section{CANAGLIFLOZIN AND METFORMIN FDC}

The canagliflozin and metformin IR FDC is indicated as an adjunct to diet and exercise to improve glycemic control in adults with T2DM. The canagliflozin and metformin IR FDC formulation is available in four dose strengths (50/500 mg, 50/1000 mg, 150/500 mg, $150 / 1000 \mathrm{mg}$ ) and should be taken twice daily with food [15]. Gradual dose escalation of metformin is recommended to limit gastrointestinal side effects associated with metformin. The twice-daily dose of canagliflozin should not exceed $150 \mathrm{mg}$ (total daily dose [TDD] of $300 \mathrm{mg}$ ), and canagliflozin should be restricted to $50 \mathrm{mg}$ twice daily (TDD of $100 \mathrm{mg}$ ) for patients with estimated glomerular filtration rate (eGFR) $\geq 45$ to $<60 \mathrm{~mL} / \mathrm{min} / 1.73 \mathrm{~m}^{2}$ [15]. An oral FDC containing immediate-release canagliflozin and metformin XR in a bilayer tablet formulation was recently approved in the USA [17]; the XR FDC formulation was under development during the writing of this article and will be reviewed separately in a future publication.

\section{PHARMACOLOGY AND BIOEQUIVALENCE}

Findings from phase 1 pharmacokinetic, bioequivalence, and food-effect studies of canagliflozin have confirmed that there are no clinically relevant differences between single-pill FDCs of canagliflozin and metformin IR compared with concomitant administration of the individual components $[18,19]$. Phase 1 pharmacodynamic study results have also shown that there are no clinically meaningful differences between the once-daily canagliflozin dosing used in the phase 3 program, which is approved as a single-component formulation [20], and the same TDD administered twice daily, which is used in the FDC with metformin IR [15, 21]. No safety differences have been observed between the FDC of canagliflozin and metformin IR and coadministration of the individual components $[18,19]$, or between once-daily vs twice-daily dosing of canagliflozin [21]. Efficacy results from a dose-ranging phase 2 study of canagliflozin as add-on to metformin confirmed the dose selections of canagliflozin 100 and $300 \mathrm{mg}$ used in the phase 3 program [22]. A subsequent phase 2 study established that twice-daily treatment with canagliflozin (50 or $150 \mathrm{mg}$ ) in patients with T2DM inadequately controlled with metformin monotherapy was comparable to results observed in phase 3 studies of once-daily canagliflozin (100 or $300 \mathrm{mg}$ ) added on to metformin monotherapy [23].

\section{PHASE 3 STUDIES \\ OF CANAGLIFLOZIN \\ IN COMBINATION WITH METFORMIN}

Canagliflozin has been evaluated in an extensive clinical development program, but no phase 3 clinical trials have been conducted on the canagliflozin/metformin FDC. The efficacy and safety of the canagliflozin/ metformin FDC is supported by data from six phase 3 studies or substudies of once-daily canagliflozin 100 or $300 \mathrm{mg}$ in patients with T2DM as add-on to metformin with or without other AHAs, and a phase 3 initial combination therapy study of canagliflozin plus metformin $\mathrm{XR}$, which also evaluated canagliflozin versus metformin monotherapy (Table 1) [16, 24-30]. 
Table 1 Study design and patient populations of phase 3 studies of canagliflozin in combination with metformin \pm other AHAs in patients with T2DM $[16,24-30]$

\begin{tabular}{|c|c|c|c|c|}
\hline Study & Study design & Key inclusion criteria & Background therapy & Patients \\
\hline $\begin{array}{l}\text { Initial } \\
\text { combination } \\
\text { with } \\
\text { CANA + MET } \\
{[16]}\end{array}$ & $\begin{array}{l}\text { Initial combination } \\
\text { therapy with } \\
\text { CANA + MET vs } \\
\text { each component } \\
\text { for } 26 \text { weeks }\end{array}$ & $\begin{array}{l}18-75 \text { years old; } \\
\text { HbAlc } 7.5-12.0 \% \text {; } \\
\text { eGFR } \geq 60 \mathrm{~mL} / \mathrm{min} / \\
1.73 \mathrm{~m}^{2}\end{array}$ & $\begin{array}{l}\text { Drug-naïve patients } \\
\text { (not on AHA therapy } \\
\text { or off for } \geq 12 \text { weeks } \\
\text { before screening) }\end{array}$ & $\begin{array}{l}N=1186 ; \text { CANA } \\
100 \mathrm{mg} / \mathrm{MET}, \\
n=237 ; \mathrm{CANA} \\
300 \mathrm{mg} / \mathrm{MET}, \\
n=237 ; \mathrm{CANA} \\
100 \mathrm{mg}, n=237 ; \\
\text { CANA } 300 \mathrm{mg}, \\
n=238 ; \mathrm{MET}, \\
n=237\end{array}$ \\
\hline $\begin{array}{l}\text { Add-on to MET vs } \\
\text { PBO/SITA [24] }\end{array}$ & $\begin{array}{l}\text { PBO-controlled, } \\
\text { 26-week core } \\
\text { period; } \\
\text { active-controlled } \\
\text { (vs SITA), 26-week } \\
\text { extension period }\end{array}$ & $\begin{array}{l}18-80 \text { years old; } \\
\text { HbAlc } 7.0-10.5 \% \text {; } \\
\text { eGFR } \geq 55 \mathrm{~mL} / \mathrm{min} / \\
1.73 \mathrm{~m}^{2 *}\end{array}$ & $\begin{array}{l}\text { Stable MET dose } \\
(\geq 2000 \mathrm{mg} / \text { day } \\
\text { [or } \geq 1500 \mathrm{mg} / \text { day if } \\
\text { unable to tolerate a } \\
\text { higher dose] }) \text { for } \\
\geq 8 \text { weeks }\end{array}$ & $\begin{array}{l}N=1284 ; \mathrm{PBO} / \mathrm{SITA}, \\
n=183 ; \text { SITA } \\
100 \mathrm{mg}, n=366 ; \\
\text { CANA } 100 \mathrm{mg}, \\
n=368 ; \text { CANA } \\
300 \mathrm{mg}, n=367\end{array}$ \\
\hline $\begin{array}{l}\text { Add-on to MET vs } \\
\text { GLIM }[25,30]\end{array}$ & $\begin{array}{l}\text { Active-controlled } \\
\text { (vs GLIM) } \\
\text { 52-week core } \\
\text { period and } \\
\text { 52-week extension }\end{array}$ & $\begin{array}{l}18-80 \text { years old; } \\
\text { HbAlc } 7.0-9.5 \% \text {; } \\
\text { eGFR } \geq 55 \mathrm{~mL} / \mathrm{min} / \\
1.73 \mathrm{~m}^{2 *}\end{array}$ & $\begin{array}{l}\text { Stable MET dose } \\
\quad(\geq 2000 \mathrm{mg} / \text { day } \\
\text { [or } \geq 1500 \mathrm{mg} / \text { day if } \\
\text { unable to tolerate } \\
\text { higher dose]) for } \\
\geq 10 \text { weeks }\end{array}$ & $\begin{array}{l}N=1450 ; \text { GLIM } \\
n=482 ; \text { CANA } \\
100 \mathrm{mg}, n=483 ; \\
\text { CANA } 300 \mathrm{mg} \\
n=485\end{array}$ \\
\hline $\begin{array}{l}\text { Add-on to } \\
\text { MET + SU vs } \\
\text { SITA [28] }\end{array}$ & $\begin{array}{l}\text { Active-controlled } \\
\text { (vs SITA), 52-week } \\
\text { treatment period }\end{array}$ & $\begin{array}{l}\geq 18 \text { years old; } \\
\text { HbAlc } 7.0-10.5 \% \text {; } \\
\text { eGFR } \geq 55 \mathrm{~mL} / \mathrm{min} / \\
\quad 1.73 \mathrm{~m}^{2 *}\end{array}$ & $\begin{array}{l}\text { Stable MET dose } \\
(\geq 2000 \mathrm{mg} / \text { day } \\
\text { [or } \geq 1500 \mathrm{mg} / \text { day if } \\
\text { unable to tolerate a } \\
\text { higher dose]) and SU } \\
\text { (at least half of } \\
\text { maximally labeled } \\
\text { dose) for } \geq 8 \text { weeks }\end{array}$ & $\begin{array}{l}N=755 ; \text { CANA } \\
300 \mathrm{mg}, n=377 ; \\
\text { SITA } 100 \mathrm{mg}, \\
n=378\end{array}$ \\
\hline $\begin{array}{l}\text { Add-on to } \\
\text { MET + SU vs } \\
\text { PBO [27] }\end{array}$ & $\begin{array}{l}\text { PBO-controlled, } \\
\text { 26-week core } \\
\text { period and } \\
\text { 26-week extension } \\
\text { period }\end{array}$ & $\begin{array}{l}18-80 \text { years old; } \\
\text { HbAlc } 7.0-10.5 \% \text {; } \\
\text { eGFR } \geq 55 \mathrm{~mL} / \mathrm{min} / \\
1.73 \mathrm{~m}^{2 *}\end{array}$ & $\begin{array}{l}\text { Stable MET dose } \\
(\geq 2000 \mathrm{mg} / \text { day } \\
\text { [or } \geq 1500 \mathrm{mg} / \text { day if } \\
\text { unable to tolerate a } \\
\text { higher dose]) and SU } \\
\text { (at least half of } \\
\text { maximally labeled } \\
\text { dose) for } \geq 8 \text { weeks }\end{array}$ & $\begin{array}{l}N=469, \text { PBO } \\
n=156 ; \text { CANA } \\
100 \mathrm{mg}, n=157 ; \\
\text { CANA } 300 \mathrm{mg} \\
n=156\end{array}$ \\
\hline
\end{tabular}


Table 1 continued

\begin{tabular}{|c|c|c|c|c|}
\hline Study & Study design & Key inclusion criteria & Background therapy & Patients \\
\hline $\begin{array}{l}\text { Add-on to } \\
\text { MET + PIO vs } \\
\text { PBO/SITA [26] }\end{array}$ & $\begin{array}{l}\text { PBO-controlled, } \\
\text { 26-week core } \\
\text { period; } \\
\text { active-controlled } \\
\text { (vs SITA), 26-week } \\
\text { extension period }\end{array}$ & $\begin{array}{l}\text { 18-80 years old; } \\
\text { HbAlc } 7.0-10.5 \% \\
\text { eGFR } \geq 55 \mathrm{~mL} / \\
\min / 1.73 \mathrm{~m}^{2 *}\end{array}$ & $\begin{array}{l}\text { Stable MET dose } \\
\qquad \begin{array}{l}\text { ( } \geq 2000 \mathrm{mg} / \text { day } \\
\text { [or } \geq 1500 \mathrm{mg} / \text { day if } \\
\text { unable to tolerate a } \\
\text { higher dose] }) \text { and PIO } \\
30 \text { or } 45 \mathrm{mg} / \text { day for } \\
\geq 8 \text { weeks }\end{array}\end{array}$ & $\begin{array}{l}N=342 ; \mathrm{PBO} / \mathrm{SITA}, \\
n=115 ; \mathrm{CANA} \\
100 \mathrm{mg}, n=113 ; \\
\text { CANA } 300 \mathrm{mg}, \\
n=114\end{array}$ \\
\hline $\begin{array}{l}\text { Add-on to } \\
\qquad \mathrm{MET}+\text { insulin } \\
\text { vs PBO [29] }\end{array}$ & $\begin{array}{l}\text { Prespecified } 18 \text {-week } \\
\text { substudy of a } \\
\text { subset of patients } \\
\text { from the ongoing } \\
\text { PBO-controlled } \\
\text { CANVAS trial }\end{array}$ & $\begin{array}{l}\geq 30 \text { years old with } \\
\text { documented, } \\
\text { symptomatic, } \\
\text { atherosclerotic } \\
\text { cardiovascular } \\
\text { disease, or } \geq 50 \text { years } \\
\text { old with } \geq 2 \\
\text { cardiovascular risk } \\
\text { factors at screening; } \\
\text { HbAlc } 7.0-10.5 \% ; \\
\text { eGFR } \geq 30 \mathrm{~mL} / \\
\text { min } / 1.73 \mathrm{~m}^{2}\end{array}$ & $\begin{array}{l}\text { Stable MET } \\
\qquad \begin{array}{l}\text { dose }(\geq 2000 \mathrm{mg} / \text { day }) \\
\text { and insulin } \\
(\geq 30 \text { IU/day; basal } \\
\text { and/or bolus })\end{array}\end{array}$ & $\begin{array}{l}N=432 ; \mathrm{PBO}, \\
n=145 ; \mathrm{CANA} \\
100 \mathrm{mg}, n=139 ; \\
\text { CANA } 300 \mathrm{mg}, \\
n=148\end{array}$ \\
\hline
\end{tabular}

$A H A$ antihyperglycemic agent, T2DM type 2 diabetes mellitus, $C A N A$ canagliflozin, $M E T$ metformin, $e G F R$ estimated glomerular filtration rate, PBO placebo, SITA sitagliptin, GLIM glimepiride, SU sulfonylurea, PIO pioglitazone, CANVAS CANagliflozin cardioVascular Assessment Study

* The required eGFR was $\geq 60 \mathrm{~mL} / \mathrm{min} / 1.73 \mathrm{~m}^{2}$ if based on restriction of metformin use in the local label

Key efficacy analyses in these studies included changes from baseline in HbA1c, body weight, and systolic BP (Tables 2, 3, 4); safety and tolerability were assessed on the basis of adverse event (AE) reports.

\section{Efficacy}

\section{Initial Combination Therapy} with Canagliflozin and Metformin

A 26-week initial combination therapy study assessed the efficacy and safety of canagliflozin and metformin XR versus canagliflozin or metformin monotherapy in drug-naïve patients [16]. Greater reductions in HbA1c were seen with canagliflozin $100 \mathrm{mg} /$ metformin and canagliflozin $300 \mathrm{mg} /$ metformin compared with metformin alone at 26 weeks $(-1.77 \%,-1.78 \%$, and $-1.30 \%$, respectively; $P=0.001$ for both comparisons; Table 2). Canagliflozin 100 and $300 \mathrm{mg}$ monotherapy were noninferior in $\mathrm{HbA} 1 \mathrm{c}$ lowering compared with metformin $(-1.37 \%$, $-1.42 \%$, and $-1.30 \%$, respectively). A greater proportion of patients achieved HbA1c $<7.0 \%$ with both canagliflozin $100 \mathrm{mg} / \mathrm{metformin}$ and canagliflozin $\quad 300 \mathrm{mg} / \mathrm{metformin}$ than metformin alone at week 26 (49.6, 56.8, and $43.0 \%$, respectively; $P=0.027$ for canagliflozin $100 \mathrm{mg} / \mathrm{metformin}$ vs metformin and $P=0.016$ for canagliflozin $300 \mathrm{mg} /$ metformin vs metformin). Canagliflozin $100 \mathrm{mg} /$ metformin 


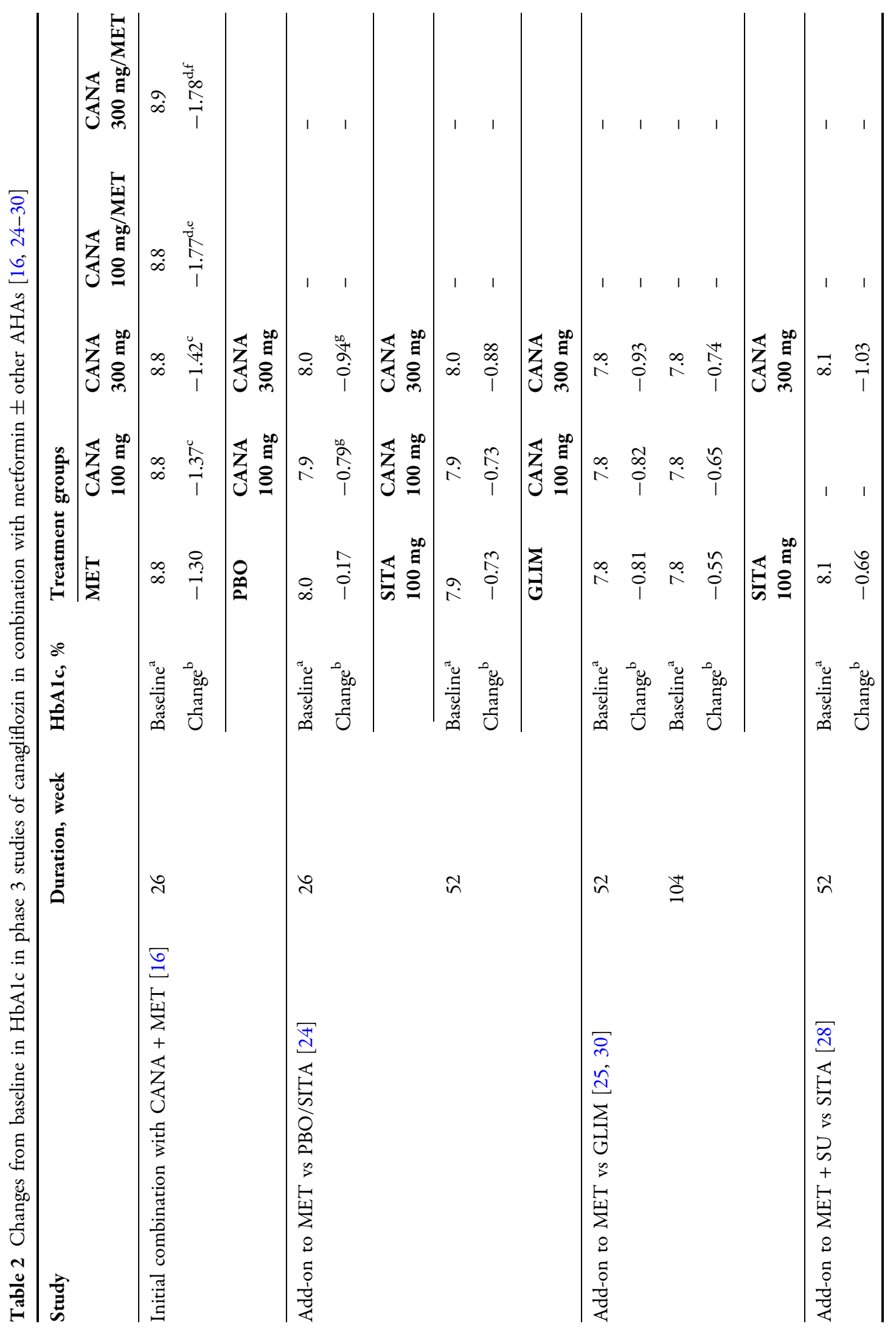




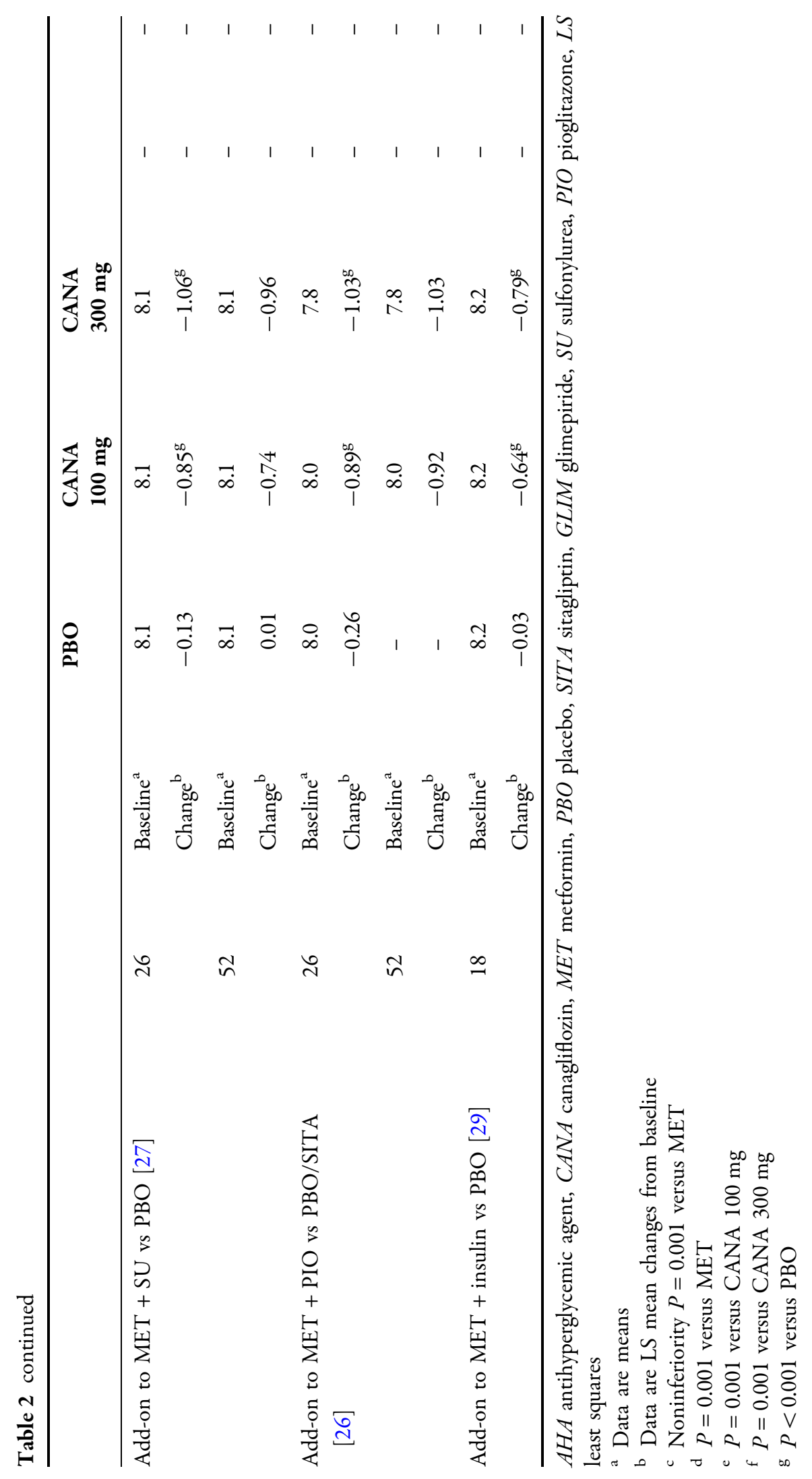




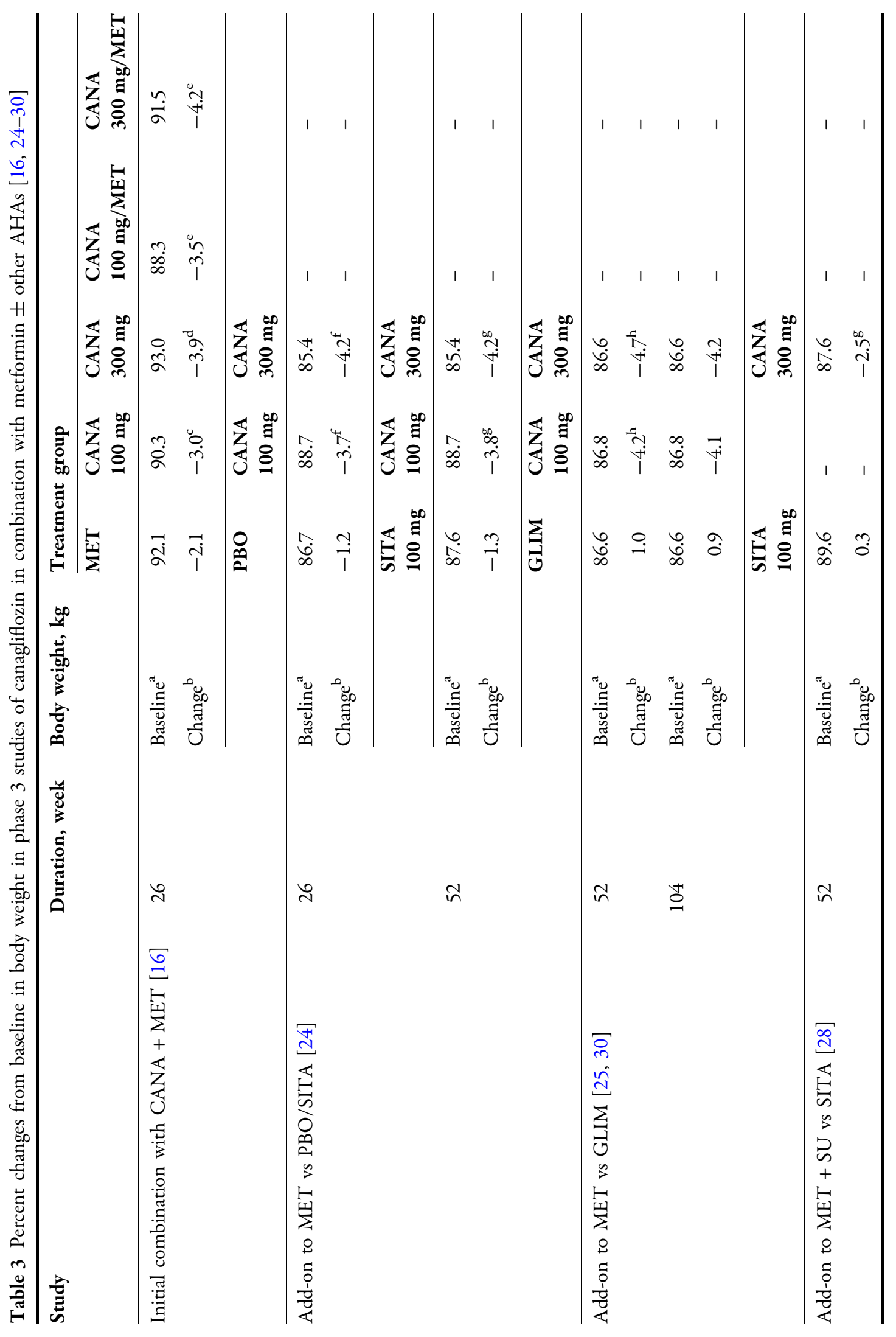




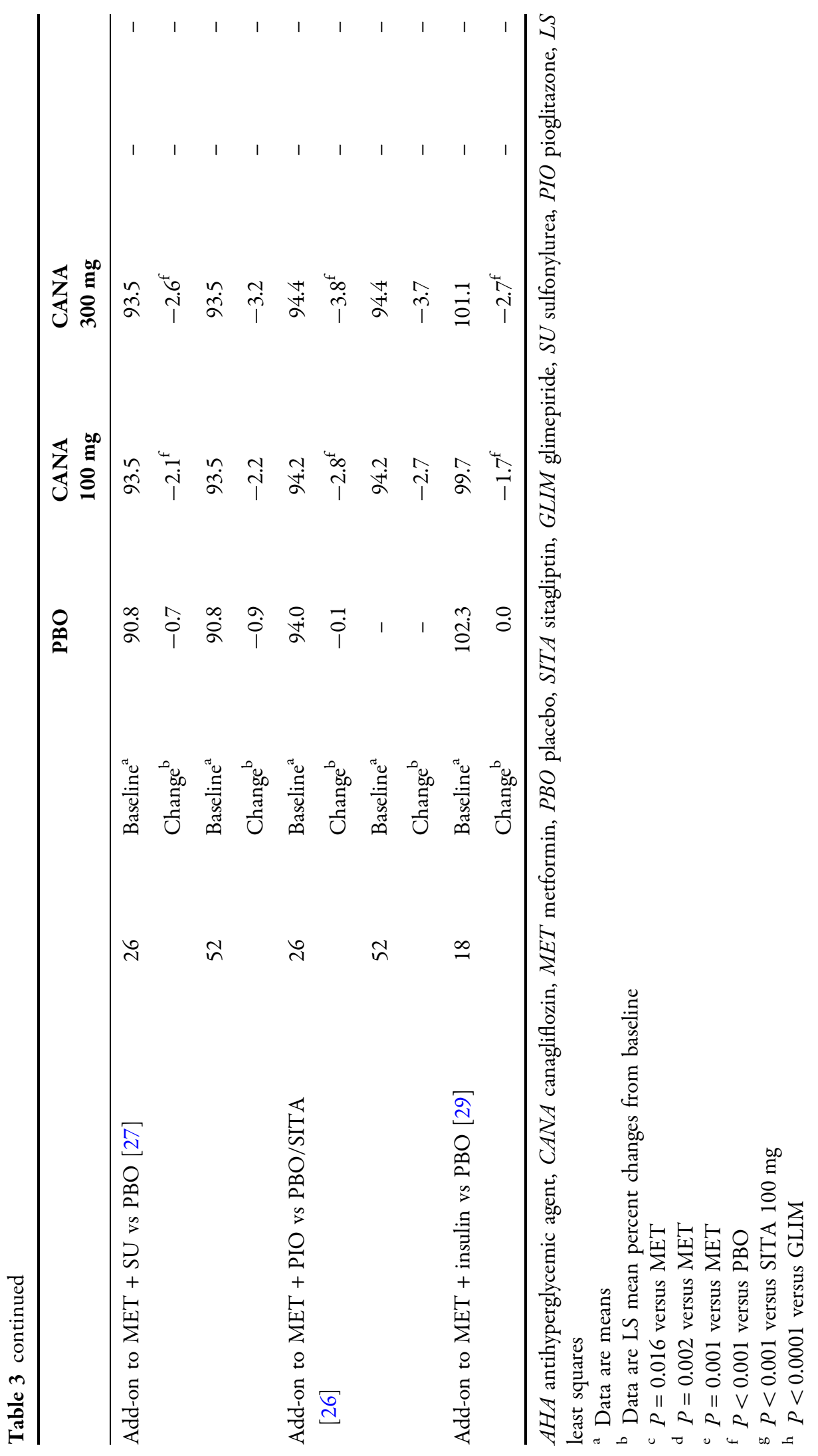




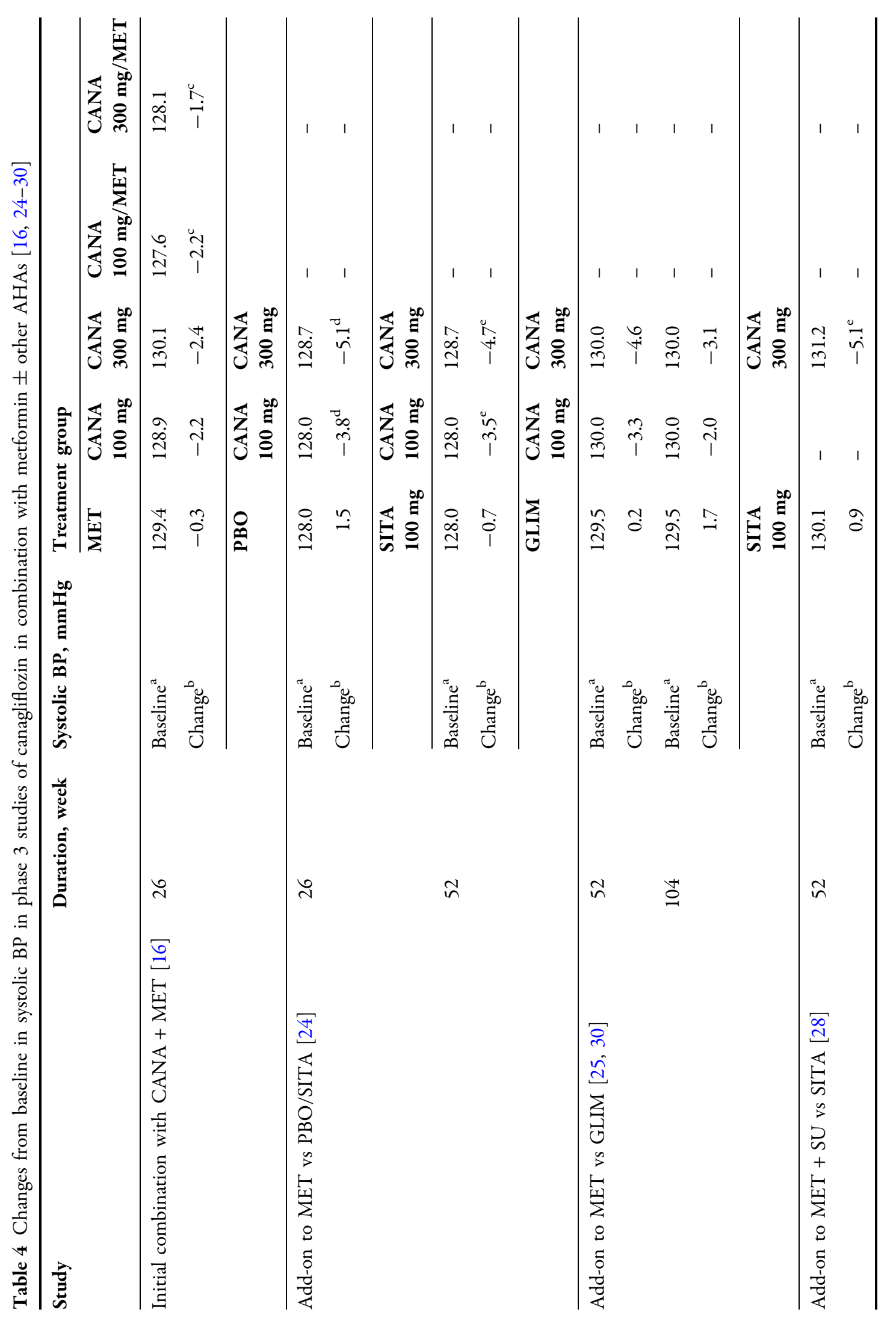




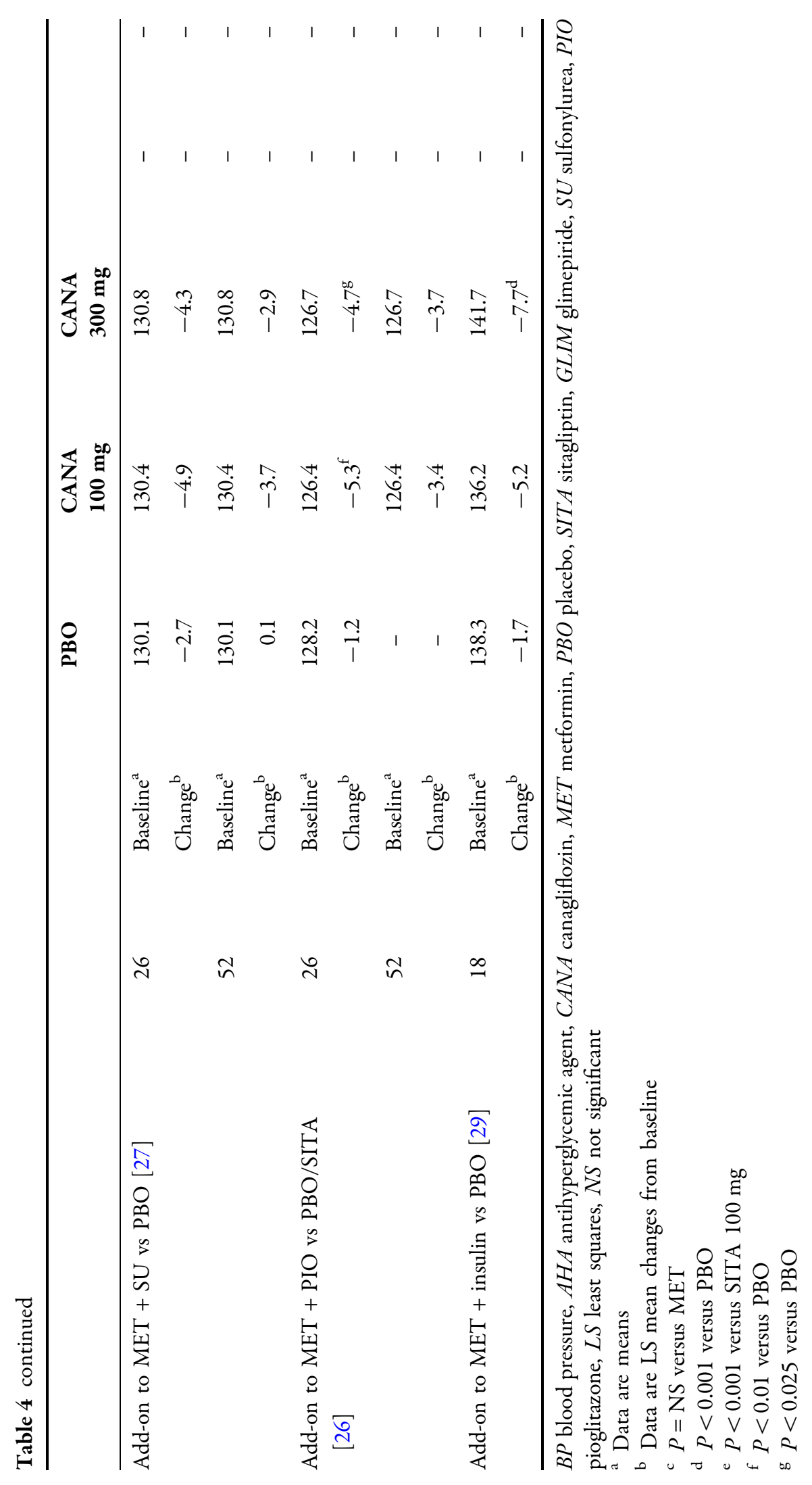


and canagliflozin $300 \mathrm{mg} / \mathrm{metformin}$ provided greater body weight reductions compared with metformin alone $(-3.5 \%,-4.2 \%$, and $-2.1 \%$; $P=0.001$ for both comparisons; Table 3). Reductions in systolic BP were numerically greater with canagliflozin $100 \mathrm{mg} / \mathrm{metformin}$ and canagliflozin $\quad 300 \mathrm{mg} / \mathrm{metformin}$ compared with metformin alone $(-2.2,-1.7$, and $-0.3 \mathrm{mmHg}$, respectively; Table 4 ).

\section{Canagliflozin as Dual Therapy with Metformin}

A 52-week study assessed the efficacy and safety of canagliflozin 100 and $300 \mathrm{mg}$ versus placebo at week 26 and versus sitagliptin $100 \mathrm{mg}$ as add-on to metformin [24]. Reductions in HbA1c at week 26 were greater with canagliflozin 100 and $300 \mathrm{mg}$ compared with placebo $(-0.79 \%$, $-0.94 \%$, and $-0.17 \%$, respectively; $P<0.001$ for both comparisons; Table 2). At week 52, canagliflozin $100 \mathrm{mg}$ was noninferior and canagliflozin $300 \mathrm{mg}$ was statistically superior to sitagliptin $100 \mathrm{mg}$ in $\mathrm{HbA1c}$ lowering $(-0.73 \%,-0.88 \%$, and $-0.73 \%$, respectively; Table 2). A greater proportion of patients achieved HbA1c $<7.0 \%$ with canagliflozin 100 and $300 \mathrm{mg}$ compared to placebo at week 26 (46\%, 58\%, and 30\%, respectively) and compared with sitagliptin $100 \mathrm{mg}$ at week 52 (55\%, 41\%, and 51\%, respectively). Canagliflozin 100 and $300 \mathrm{mg}$ significantly reduced body weight compared with placebo $(-3.7 \%,-4.2 \%$, and $-1.2 \%$, respectively; $\mathrm{P}<0.001$ for both comparisons; Table 3) at week 26. Greater reductions in body weight were seen with canagliflozin 100 and $300 \mathrm{mg}$ versus sitagliptin $100 \mathrm{mg}$ at week $52(-3.8 \%$, $-4.2 \%$, and $-1.3 \%$, respectively; $P<0.001$ for both comparisons; Table 3). At week 26, systolic $\mathrm{BP}$ reductions were seen with canagliflozin 100 and $\quad 300 \mathrm{mg} \quad(-3.8$ and $-5.1 \mathrm{mmHg}$, respectively) compared with an increase of
$1.5 \mathrm{mmHg}$ with placebo $(P<0.001$ for both comparisons; Table 4). At week 52, reductions in systolic BP were larger with canagliflozin 100 and $300 \mathrm{mg}$ compared with sitagliptin $100 \mathrm{mg}$ $(-3.5,-4.7$, and $-0.7 \mathrm{mmHg}$, respectively; $P<0.001$ for both comparisons; Table 4).

A 104-week study assessed the efficacy and safety of canagliflozin 100 and $300 \mathrm{mg}$ versus glimepiride as add-on to metformin at weeks 52 and 104 [25, 30]. At week 52, canagliflozin $100 \mathrm{mg}$ demonstrated noninferiority and canagliflozin $300 \mathrm{mg}$ demonstrated superiority in HbA1c lowering compared with glimepiride $(-0.82 \%,-0.93 \%$, and $-0.81 \%$, respectively; Table 2) [25]. Reductions in HbA1c were sustained at week $104(-0.65 \%,-0.74 \%$, and $-0.55 \%$, respectively; Table 2) [30]. At week 52, 54,60 , and $56 \%$ of patients achieved HbA1c $<7.0 \%$ with canagliflozin 100 and $300 \mathrm{mg}$ and glimepiride, respectively [25]. At week 104, 43, 50 , and $44 \%$ of patients achieved HbA1c $<7.0 \%$, respectively [30]. Body weight at week 52 was significantly reduced with canagliflozin 100 and $300 \mathrm{mg} \quad(-4.2 \%$ and $-4.7 \%$, respectively), compared with a $1.0 \%$ increase with glimepiride $(P<0.0001$ for both comparisons; Table 3) [25]. Reductions in body weight with canagliflozin 100 and $300 \mathrm{mg}$ versus glimepiride were maintained at week 104 $(-4.1 \%,-4.2 \%$, and $0.9 \%$, respectively; Table 3) [30]. Reductions in systolic BP were seen with canagliflozin 100 and $300 \mathrm{mg}(-3.3$ and $-4.6 \mathrm{mmHg}$ ) compared to an increase of $0.2 \mathrm{mmHg}$ with glimepiride at 52 weeks (Table 4) [25]. At week 104, changes in systolic BP were $-2.0,-3.1$, and $1.7 \mathrm{mmHg}$, respectively (Table 4) [30].

\section{Canagliflozin in Combination with Metformin Plus Other AHAs}

A 52-week study evaluated the efficacy and safety of canagliflozin $300 \mathrm{mg}$ versus sitagliptin 
$100 \mathrm{mg}$ as add-on to metformin plus sulfonylurea [28]. Canagliflozin $300 \mathrm{mg}$ demonstrated superiority in HbA1c lowering versus sitagliptin $100 \mathrm{mg}$ at week $52(-1.03 \%$ and $-0.66 \%$, respectively; Table 2 ). The greater HbA1c lowering with canagliflozin $300 \mathrm{mg}$ was accompanied by a greater proportion of patients achieving HbA1c $<7.0 \%$ with canagliflozin $300 \mathrm{mg}$ versus sitagliptin $100 \mathrm{mg} \quad(48 \%$ vs 35\%). Canagliflozin $300 \mathrm{mg}$ significantly reduced body weight compared to sitagliptin $100 \mathrm{mg}$ ( $-2.5 \%$ vs $0.3 \% ; P<0.001$; Table 3$)$. Canagliflozin $300 \mathrm{mg}$ also significantly reduced systolic BP $(-5.1 \mathrm{mmHg})$ versus an increase of $0.9 \mathrm{mmHg}$ with sitagliptin $100 \mathrm{mg}(P<0.001$; Table 4).

A placebo-controlled study evaluated the efficacy and safety of canagliflozin 100 and $300 \mathrm{mg}$ as add-on to metformin plus sulfonylurea at weeks 26 and 52 [27]. Canagliflozin 100 and $300 \mathrm{mg}$ provided greater reductions in HbA1c compared with placebo at week $26(-0.85 \%,-1.06 \%$, and $-0.13 \%$, respectively; $P<0.001$ for both comparisons); these reductions were maintained at week 52 $(-0.74 \%,-0.96 \%$, and $0.01 \%$, respectively; Table 2). A greater proportion of patients receiving canagliflozin 100 and $300 \mathrm{mg}$ achieved HbA1c $<7.0 \%$ at week 26 than those receiving placebo (43, 57, and 18\%, respectively; $P<0.001$ for both comparisons). At week 52, 39, 53, and $19 \%$ of patients achieved HbA1c $<7.0 \%$ with canagliflozin 100 and $300 \mathrm{mg}$ and placebo, respectively. Significant body weight reductions were seen with canagliflozin 100 and $300 \mathrm{mg}$ compared with placebo at week $26(-2.1 \%,-2.6 \%$, and $-0.7 \%$, respectively; $P<0.001$ for both comparisons) and were sustained at week 52 $(-2.2 \%,-3.2 \%$, and $-0.9 \%$, respectively; Table 3). Canagliflozin 100 and $300 \mathrm{mg}$ provided numerically greater reductions in systolic BP compared with placebo at week 26 $(-4.9,-4.3$, and $-2.7 \mathrm{mmHg}$, respectively); changes in systolic BP were $-3.7,-2.9$, and $0.1 \mathrm{mmHg}$, respectively, at week 52 (Table 4).

In a study as add-on to metformin plus pioglitazone, the efficacy and safety of canagliflozin 100 and $300 \mathrm{mg}$ were assessed versus placebo at week 26 [26]. The study included a 26-week extension during which patients receiving placebo were switched to sitagliptin $100 \mathrm{mg}$; this arm was not included in efficacy evaluations at week 52 . At week 26, greater reductions in $\mathrm{HbA1c}$ were seen with canagliflozin 100 and $300 \mathrm{mg}$ versus placebo $(-0.89 \%,-1.03 \%$, and $-0.26 \%$, respectively; $P<0.001$ for both comparisons; Table 2). A greater proportion of patients achieved $\mathrm{HbA1c}$ $<7.0 \%$ with canagliflozin 100 and $300 \mathrm{mg}$ versus placebo $(47,64$, and 33\%, respectively). Reductions in body weight were greater with canagliflozin 100 and $300 \mathrm{mg}$ compared with placebo at week $26(-2.8 \%,-3.8 \%$, and $-0.1 \%$, respectively; $P<0.001$ for both comparisons; Table 3). Similarly, canagliflozin 100 and $300 \mathrm{mg}$ provided larger reductions in systolic BP compared with placebo $(-5.3,-4.7$, and $-1.2 \mathrm{mmHg}$, respectively; Table 4). Reductions in $\mathrm{HbA1c}$, body weight, and systolic BP with canagliflozin 100 and $300 \mathrm{mg}$ were maintained at week 52 (Tables 2, 3, 4).

In a prespecified analysis of a subset of patients with either a history or high risk of cardiovascular disease enrolled in the CANagliflozin cardioVascular Assessment Study (CANVAS) who were on background metformin plus insulin, the efficacy and safety of canagliflozin 100 and $300 \mathrm{mg}$ were assessed versus placebo at week 18 [29]. Canagliflozin 100 and $300 \mathrm{mg}$ reduced HbA1c compared with placebo $(-0.64 \%,-0.79 \%$, and $0.03 \%$, respectively; $P<0.001$ for both comparisons; Table 2). A greater proportion of patients 
achieved HbA1c $<7.0 \%$ with canagliflozin 100 and $300 \mathrm{mg}$ versus placebo (19\%, 29\%, and 9\%, respectively; $P=0.008$ for canagliflozin $100 \mathrm{mg}$ vs placebo; $P<0.001$ for canagliflozin $300 \mathrm{mg}$ vs placebo). Significant reductions in body weight were seen with canagliflozin 100 and $300 \mathrm{mg}$ compared with placebo $(-1.7 \%,-2.7 \%$, and $0.0 \%$, respectively; $P<0.001$ for both comparisons; Table 3). Canagliflozin 100 and $300 \mathrm{mg}$ provided larger reductions in systolic BP compared with placebo $(-5.2,-7.7$, and $-1.7 \mathrm{mmHg}$, respectively; $P<0.001$ for canagliflozin $300 \mathrm{mg}$ vs placebo; Table 4).

\section{Safety and Tolerability}

Canagliflozin in combination with metformin has been associated with a favorable safety and tolerability profile across phase 3 studies (Table 5) [16, 24-30]. Rates of AEs leading to discontinuation and serious AEs were generally low with canagliflozin versus comparators $[16,24-30]$. Not surprisingly, the incidence of AEs related to SGLT2 inhibition (e.g., genital mycotic infections, urinary tract infections, osmotic diuresis-related AEs) was generally higher with canagliflozin versus comparators [16, 24-30]. Risk factors for genital mycotic infection include a prior history of recurrent genital mycotic infections and uncircumcision. Older patients, those with reduced renal function, those with reduced BP, and those taking diuretics may be vulnerable to the volume depletion effects of canagliflozin. These patients, in particular, should be advised to drink plenty of non-sugar-containing fluids, and consideration should be given to reducing or holding their diuretics until after they are reassessed. Gastrointestinal intolerability is a common side effect of metformin [9]; however, the combination of canagliflozin and metformin has not been associated with an increased incidence of gastrointestinal-related AEs (i.e., diarrhea, nausea, and vomiting) [31]. Reports of hypoglycemia have been generally low with canagliflozin among patients not on background therapy associated with hypoglycemia (i.e., sulfonylurea or insulin) and in patients treated with initial canagliflozin/metformin combination therapy [16, 24-30].

No serious AEs of diabetic ketoacidosis have been seen with canagliflozin as add-on to metformin alone or in combination with pioglitazone, or in the subset of patients from the CANVAS trial on background metformin plus insulin [32]. There was one serious ketoacidosis $\mathrm{AE}$ with canagliflozin $100 \mathrm{mg}$ in the placebo-controlled add-on to metformin plus sulfonylurea study [27], and the patient subsequently received a diagnosis of type 1 diabetes mellitus [32]. In the initial combination study [16], there was one serious $\mathrm{AE}$ of ketoacidosis in a patient in the canagliflozin $300 \mathrm{mg}$ group with confounding factors that included acute infection, chronic pancreatitis, and heart failure class II [32]. It is important to note that patients with $\mathrm{HbA1c}$ $>10.5 \%$ were excluded from these studies.

The incidence of fractures was low and similar with canagliflozin versus comparators across the phase 3 program in non-CANVAS studies, including those as add-on to metformin with or without other AHAs [33].

Across studies, canagliflozin was generally associated with reductions in triglycerides and increases in both high-density lipoprotein cholesterol and low-density lipoprotein cholesterol [16, 24-30]. Changes in laboratory parameters (i.e., alanine aminotransferase, aspartate aminotransferase, bilirubin, blood urea nitrogen, creatinine, urate, and hemoglobin) with canagliflozin were not clinically meaningful. Treatment with 
Table 5 Safety summary from phase 3 studies of canagliflozin in combination with metformin [16, 24-30]

Parameter Combination of CANA + MET

Overall safety and tolerability

Generally well tolerated; low incidence of AEs leading to study discontinuation and serious AEs

Genital mycotic infections

Higher incidence versus PBO, SITA, and GLIM; low incidence with CANA/MET in initial combination therapy

Generally mild or moderate in intensity; few led to study discontinuation

Generally higher incidence in women than in men; more likely to occur in patients with a history of genital mycotic infections and in uncircumcised males

UTIs

Low incidence across studies; higher incidence versus GLIM and PBO; similar incidence compared with SITA

Generally mild to moderate in intensity and few led to discontinuation; low incidence of serious or upper UTIs

Osmotic diuresis-related AEs (e.g., pollakiuria, Generally low incidence polyuria, thirst)

Higher incidence versus PBO, SITA, and GLIM; few led to study discontinuation

Volume depletion-related AEs (e.g., orthostatic Generally low incidence; dose-dependent increase in incidence seen across hypotension, dizziness postural) studies

Incidence was higher in patients taking loop diuretics, in patients with moderate renal impairment (i.e., eGFR $\geq 30$ to $<60 \mathrm{~mL} / \mathrm{min} / 1.73 \mathrm{~m}^{2}$ ), and in patients aged $\geq 75$ years

Gastrointestinal-related AEs (i.e., diarrhea, nausea, vomiting)

No increase in incidence with CANA as add-on to MET \pm other AHAs versus PBO, SITA, or GLIM; incidence was low with CANA/MET as initial combination therapy

Hypoglycemia

Low incidence when not used in combination with background AHAs associated with hypoglycemia (e.g., SU or insulin)

Significantly lower incidence versus GLIM

Slightly higher incidence with CANA as add-on to MET versus SITA; similar incidence with CANA as add-on to MET + SU versus SITA with greater HbAlc lowering with CANA; incidence with CANA/ MET was similar to MET in initial combination therapy

Diabetic ketoacidosis AEs

Low incidence across studies of severe hypoglycemia episodes

Low incidence across studies

No serious AEs of diabetic ketoacidosis with CANA as add-on to MET, $\mathrm{MET}+\mathrm{PIO}$, or in the MET + insulin subset of CANVAS

1 serious event each with CANA $100 \mathrm{mg}$ as add-on to MET + SU and with CANA $300 \mathrm{mg}$ as initial combination therapy

Incidence low and similar across studies in non-CANVAS studies 
Table 5 continued

\begin{tabular}{lc}
\hline Parameter & Combination of CANA + MET \\
\hline Fasting plasma lipids & Triglycerides were generally reduced across studies \\
& $\begin{array}{c}\text { High-density lipoprotein cholesterol and low-density lipoprotein } \\
\text { cholesterol were generally increased across studies }\end{array}$ \\
Clinical laboratory parameters & $\begin{array}{l}\text { Transient reduction in eGFR early in treatment that attenuated over } \\
\text { time }\end{array}$ \\
No clinically meaningful changes in alanine aminotransferase, aspartate \\
aminotransferase, bilirubin, blood urea nitrogen, creatinine, urate, and \\
hemoglobin \\
Small changes in serum electrolytes (i.e., potassium, magnesium, \\
phosphate)
\end{tabular}

$C A N A$ canagliflozin, MET metformin, AE adverse event, PBO placebo, SITA sitagliptin, GLIM glimepiride, UTI urinary tract infection, $e G F R$ estimated glomerular filtration rate, $S U$ sulfonylurea, $P I O$ pioglitazone, CANVAS CANagliflozin cardioVascular Assessment Study

canagliflozin in combination with metformin was associated with a transient reduction in eGFR that attenuated over time [16, 24-30].

\section{CANAGLIFLOZIN/METFORMIN FDC PLACE IN THERAPY}

Guidelines for treating patients with T2DM emphasize a personalized approach for improving glycemic control to minimize diabetes-related complications and drug-related side effects [1,2]. Metformin is typically used as a first-line pharmacotherapy for patients with T2DM [1, 2]. However, for patients unable to attain glycemic control with metformin alone, the selection of additional AHAs is warranted. In newly diagnosed patients with high initial HbA1c levels, an initial combination approach consisting of therapies with complementary mechanisms of action is recommended [1, 2]. The use of an FDC can simplify combination treatment compared to two-pill administration and can potentially provide increased therapy adherence and reduced medication errors
[34-40]. In addition, FDC therapies with variable dosing may provide for faster and greater efficacy with lower risk of AEs compared with monotherapy. FDC medications that do not directly increase the risk of hypoglycemia and do not cause weight gain, and preferably cause weight loss, may lead to increased compliance, reduced hospitalization, and better cardiorenal outcomes by reducing metabolic risk factors [34].

The AACE T2DM disease management algorithm recommends SGLT2 inhibitors as the first orally administered add-on therapy to metformin [1]; thus, an FDC of the SGLT2 inhibitor canagliflozin with metformin may be valuable for many patients. Results from phase 3 studies in patients with T2DM show that the combination of canagliflozin plus metformin, including canagliflozin and metformin as initial combination therapy, provides substantial improvements in glycemic control, along with other benefits including weight loss and reductions in systolic BP [16, 24-30]. As canagliflozin $300 \mathrm{mg}$ provided superior glycemic control to sitagliptin or glimepiride as add-on to metformin 
$[24,25,30]$, the canagliflozin/metformin combination may be a better therapeutic option than combination therapy with these other agents. Overall, canagliflozin in combination with metformin with or without other AHAs was generally well tolerated. These data support the use of the canagliflozin and metformin FDC in patients with T2DM.

Canagliflozin also demonstrated efficacy and safety in patients with T2DM and cardiovascular disease or chronic kidney disease, many of whom were on background metformin [29, 41, 42]. It has been hypothesized that canagliflozin may provide cardiovascular and renoprotective benefits, which will be assessed in ongoing outcomes studies, including CANVAS (ClinicalTrials.gov Identifier: NCT01032629), CANVAS-R (renal endpoints; NCT01989754), and Canagliflozin and Renal Events in Diabetes with Established Nephropathy Clinical Evaluation (CREDENCE; NCT02065791).

\section{CONCLUSION}

Attaining early and sustained glycemic control can reduce the risk of diabetes-related complications. For many patients with T2DM, the use of combination therapies with metformin may be valuable to help them attain their individualized glycemic goals. Across phase 3 studies, including as initial combination therapy in drug-naïve patients, canagliflozin in combination with metformin provided favorable glycemic efficacy and additional benefits of weight loss, BP reduction, and a low risk of hypoglycemia. Together, the beneficial efficacy and favorable safety profiles for canagliflozin in combination with metformin support the use of the canagliflozin and metformin FDC as a therapeutic approach in a broad range of patients with T2DM.

\section{ACKNOWLEDGEMENTS}

The studies reported here were funded by Janssen Research \& Development, LLC. Medical writing support and article processing charges were funded by Janssen Scientific Affairs, LLC. The authors were involved at all stages of manuscript development and maintained full control over the scientific content. Medical writing support was provided to the authors by Felicia Gray, PhD, of MedErgy. All named authors meet the International Committee of Medical Journal Editors (ICMJE) criteria for authorship for this manuscript, take responsibility for the integrity of the work as a whole, and have given final approval for the version to be published.

Disclosures. JA. Davidson is a consultant for Janssen Research \& Development, LLC, and a member of their speakers bureau. L. Sloan is also a member of the speakers bureau for Janssen Research \& Development, LLC.

Compliance with Ethics Guidelines. This article is based on previously conducted studies and does not involve any new studies of human or animal subjects performed by any of the authors.

Data Availability Statement. Data sharing is not applicable to this article as no datasets were generated or analyzed during the current study.

Open Access. This article is distributed under the terms of the Creative Commons Attribution-NonCommercial 4.0 International License (http://creativecommons.org/licenses/ by-nc/4.0/), which permits any noncommercial use, distribution, and reproduction in any medium, provided you give appropriate credit to 
the original author(s) and the source, provide a link to the Creative Commons license, and indicate if changes were made.

\section{REFERENCES}

1. Garber AJ, Abrahamson MJ, Barzilay JI, et al. Consensus statement by the American Association of Clinical Endocrinologists and American College of Endocrinology on the comprehensive type 2 diabetes management algorithm-2016 executive summary. Endocr Pract. 2016;22:84-113.

2. Inzucchi SE, Bergenstal RM, Buse JB, et al. Management of hyperglycemia in type 2 diabetes, 2015: a patient-centered approach: update to a position statement of the American Diabetes Association and the European Association for the Study of Diabetes. Diabetes Care. 2015;38:140-9.

3. American Diabetes Association. Standards of medical care in diabetes-2016. Diabetes Care. 2016;39:S1-108.

4. Ferrannini E. The target of metformin in type 2 diabetes. N Engl J Med. 2014;371:1547-8.

5. Buse JB, Defronzo RA, RosenstockJ, et al. The primary glucose-lowering effect of metformin resides in the gut, not the circulation: results from short-term pharmacokinetic and 12-week dose-ranging studies. Diabetes Care. 2016;39:198-205.

6. Mannucci E, Ognibene A, Cremasco F, et al. Effect of metformin on glucagon-like peptide 1 (GLP-1) and leptin levels in obese nondiabetic subjects. Diabetes Care. 2001;24:489-94.

7. Napolitano A, Miller S, Nicholls AW, et al. Novel gut-based pharmacology of metformin in patients with type 2 diabetes mellitus. PLoS One. 2014;9:e100778.

8. GLUCOPHAGE/GLUCOPHAGE ${ }^{\circledR}$ XR (metformin hydrochloride) extended-release tablets [package insert]. Princeton: Bristol-Myers Squibb Company; 2015.

9. Jabbour S, Ziring B. Advantages of extended-release metformin in patients with type 2 diabetes mellitus. Postgrad Med. 2011;123:15-23.

10. Cook MN, Girman CJ, Stein PP, Alexander CM. Initial monotherapy with either metformin or sulphonylureas often fails to achieve or maintain current glycaemic goals in patients with type 2 diabetes in UK primary care. Diabet Med. 2007;24:350-8.
11. Cook MN, Girman CJ, Stein PP, Alexander CM, Holman RR. Glycemic control continues to deteriorate after sulfonylureas are added to metformin among patients with type 2 diabetes. Diabetes Care. 2005;28:995-1000.

12. Texas Diabetes Council. Glycemic control algorithm for type 2 diabetes mellitus in adults. $2015 . \quad$ http://www.tdctoolkit.org/algorithmsguidelines/. Accessed 11 Aug 2016.

13. Chao EC, Henry RR. SGLT2 inhibition-a novel strategy for diabetes treatment. Nat Rev Drug Discov. 2010;9:551-9.

14. Rosenthal N, Meininger $\mathrm{G}$, Ways $\mathrm{K}$, et al. Canagliflozin: a sodium glucose co-transporter 2 inhibitor for the treatment of type 2 diabetes mellitus. Ann N Y Acad Sci. 2015;1358:28-43.

15. INVOKAMET ${ }^{\circledR}$ (canagliflozin and metformin hydrochloride) tablets for oral use [package insert]. Titusville: Janssen Pharmaceuticals, Inc; 2016.

16. Rosenstock J, Chuck L, González-Ortiz M, Merton K, Craig J, Capuano G. Initial combination therapy with canagliflozin plus metformin versus each component as monotherapy in drug-naïve type 2 diabetes. Diabetes Care. 2016;39:353-62.

17. INVOKAMET ${ }^{\circledR}$ XR (canagliflozin and metformin hydrochloride extended-release) tablets, for oral use. Titusville: Janssen Pharmaceuticals; 2016.

18. Devineni D, Curtin CR, Ariyawansa J, et al. Bioequivalence of canagliflozin/metformin immediate release fixed-dose combination tablets compared with concomitant administration of single components of canagliflozin and metformin in healthy fed participants. J Bioequiv Avail. 2014;6:164-73.

19. Murphy J, Wang SS, Stieltjes H, Wajs E, Devineni D. Effect of food on the pharmacokinetics of canagliflozin/metformin (150/1,000 mg) immediate-release fixed-dose combination tablet in healthy participants. Int J Clin Pharmacol Ther. 2015;53:256-64.

20. INVOKANA $^{\circledR}$ (canagliflozin) tablets, for oral use [package insert]. Titusville: Janssen Pharmaceuticals; 2016.

21. Devineni D, Polidori D, Curtin CR, et al. Pharmacokinetics and pharmacodynamics of once- and twice-daily multiple-doses of canagliflozin, a selective inhibitor of sodium glucose co-transporter 2, in healthy participants. Int J Clin Pharmacol Ther. 2015;53:438-46.

22. Rosenstock J, Aggarwal N, Polidori D, et al. Dose-ranging effects of canagliflozin, a 
sodium-glucose cotransporter 2 inhibitor, as add-on to metformin in subjects with type 2 diabetes. Diabetes Care. 2012;35:1232-8.

23. Qiu R, Capuano G, Meininger G. Efficacy and safety of twice-daily treatment with canagliflozin, a sodium glucose co-transporter 2 inhibitor, added on to metformin monotherapy in patients with type 2 diabetes mellitus. J Clin Transl Endocrinol. 2014;1:54-60.

24. Lavalle-González FJ, Januszewicz A, Davidson J, et al. Efficacy and safety of canagliflozin compared with placebo and sitagliptin in patients with type 2 diabetes on background metformin monotherapy: a randomised trial. Diabetologia. 2013;56:2582-92.

25. Cefalu WT, Leiter LA, Yoon KH, et al. Efficacy and safety of canagliflozin versus glimepiride in patients with type 2 diabetes inadequately controlled with metformin (CANTATA-SU): 52 week results from a randomised, double-blind, phase 3 non-inferiority trial. Lancet. 2013;382:941-50.

26. Forst T, Guthrie R, Goldenberg R, et al. Efficacy and safety of canagliflozin over 52 weeks in patients with type 2 diabetes on background metformin and pioglitazone. Diabetes Obes Metab. 2014;16:467-77.

27. Wilding JP, Charpentier G, Hollander $P$, et al. Efficacy and safety of canagliflozin in patients with type 2 diabetes mellitus inadequately controlled with metformin and sulphonylurea: a randomised trial. Int J Clin Pract. 2013;67:1267-82.

28. Schernthaner G, Gross JL, Rosenstock J, et al. Canagliflozin compared with sitagliptin for patients with type 2 diabetes who do not have adequate glycemic control with metformin plus sulfonylurea: a 52-week, randomized trial. Diabetes Care. 2013;36:2508-15.

29. Rosenstock J, Matthews DR, Desai M, Capuano G, Meininger G, Canovatchel W. Impact of canagliflozin added-on to insulin and metformin in type 2 diabetes: a substudy of the CANVAS trial. Poster presented at the 75th Scientific Sessions of the American Diabetes Association (ADA); June 5-9, 2015; Boston, Massachusetts.

30. Leiter LA, Yoon KH, Arias $\mathrm{P}$, et al. Canagliflozin provides durable glycemic improvements and body weight reduction over 104 weeks versus glimepiride in patients with type 2 diabetes on metformin: a randomized, double-blind, phase 3 study. Diabetes Care. 2015;38:355-64.

31. Usiskin K, Kline I, Fung A, Mayer C, Meininger G. Safety and tolerability of canagliflozin in patients with type 2 diabetes: pooled analysis of phase 3 study results. Postgrad Med. 2014;126:16-34.
32. Erondu N, Desai M, Ways K, Meininger G. Diabetic ketoacidosis and related events in the canagliflozin type 2 diabetes clinical program. Diabetes Care. 2015;38:1680-6.

33. Watts NB, Bilezikian JP, Usiskin K, et al. Effects of canagliflozin on fracture risk in patients with type 2 diabetes mellitus. J Clin Endocrinol Metab. 2016;101:157-66.

34. Bell DS. Combine and conquer: advantages and disadvantages of fixed-dose combination therapy. Diabetes Obes Metab. 2013;15:291-300.

35. Hutchins V, Zhang B, Fleurence RL, Krishnarajah G, Graham J. A systematic review of adherence, treatment satisfaction and costs, in fixed-dose combination regimens in type 2 diabetes. Curr Med Res Opin. 2011;27:1157-68.

36. Williams SA, Buysman EK, Hulbert EM, Bergeson JG, Zhang B, Graham J. Hemoglobin A1c outcomes and health care resource use in type 2 diabetes mellitus patients treated with combination oral antidiabetic drugs through step therapy and loose-dose and fixed-dose combinations. Manag Care. 2012;21:40-8.

37. Cheong C, Barner JC, Lawson KA, Johnsrud MT. Patient adherence and reimbursement amount for antidiabetic fixed-dose combination products compared with dual therapy among Texas Medicaid recipients. Clin Ther. 2008;30:1893-907.

38. Ray J, Huet D, Valentine W, Palmer A, Cugnardey $\mathrm{N}$, Renaudin C. Long-term costs and clinical outcomes associated with metformin-glibenclamide combination tablets (Glucovance $^{\circledR}$ ) in patients with type 2 diabetes sub-optimally controlled by metformin: a modelling study in the French setting. $\mathrm{Br} \mathrm{J}$ Diabetes Vasc Dis. 2008;8:39-44.

39. Colombo G, Rossi E, De Rosa M, Benedetto D, Gaddi A. Antidiabetic therapy in real practice: indicators for adherence and treatment cost. Patient Prefer Adher. 2012;6:653-61.

40. Genovese S, Tedeschi D. Effects of vildagliptin/ metformin therapy on patient-reported outcomes: work productivity, patient satisfaction, and resource utilization. Adv Ther. 2013;30:152-64.

41. Yale JF, Bakris G, Cariou B, et al. Efficacy and safety of canagliflozin in subjects with type 2 diabetes and chronic kidney disease. Diabetes Obes Metab. 2013;15:463-73.

42. Yale JF, Bakris G, Cariou B, et al. Efficacy and safety of canagliflozin over 52 weeks in patients with type 2 diabetes mellitus and chronic kidney disease. Diabetes Obes Metab. 2014;16:1016-27. 